\title{
Glutamine Cycling in Neurospora crassa
}

\author{
By JORGE CALDERÓN AND JAIME MORA* \\ Centro de Investigación sobre Fijación de Nitrógeno, UNAM, Apartado Postal 565-A, \\ Cuernavaca, Mor., México
}

(Received 18 March 1985; revised 23 May 1985)

\begin{abstract}
The accumulation of amino acids and the excretion of ammonium have been studied in various Neurospora crassa ammonium assimilation mutants, together with the labelling of glutamine in the presence of $\left[\mathrm{U}^{1+} \mathrm{C}\right]$ sucrose when $N$. crassa grows on glutamine as the nitrogen source. Ammonium coming from glutamine degradation by the $\omega$-amidase pathway is assimilated by NADP-dependent glutamate dehydrogenase and glutamine synthetase. The operation of these enzymes results in a cycling of glutamine that seems to be essential for cell growth. In addition, glutamine is also converted to glutamate by glutamate synthase.
\end{abstract}

\section{INTRODUCTION}

Glutamine is the final product of ammonium assimilation and is a nitrogen donor for biosynthetic reactions (Prusiner \& Stadtman, 1973); it has been proposed as the nitrogen metabolite responsible for nitrogen catabolite repression in several micro-organisms, including Neurospora crassa (Vaca \& Mora, 1977; Marzluf, 1981). Although glutamine has a central role in nitrogen metabolism, it is not known how it is assimilated in eukaryotic micro-organisms. We have described the operation of the $\omega$-amidase pathway that converts glutamine to 2oxoglutarate and ammonium through the action of a glutamine transaminase and an $\omega$-amidase (Espín \& Mora, 1978; Espín et al., 1979; Calderón et al., 1985). In addition, we have found that NADP-dependent glutamate dehydrogenase (GDH) participates in the assimilation of ammonium liberated by the $\omega$-amidase pathway (Calderón et al., 1985). An NADH-dependent glutamate synthase (GOGAT) that converts glutamine to glutamate has been found in $N$. crassa (Hummelt \& Mora, 1980a); it may also contribute to glutamine nitrogen distribution. In $N$. crassa, glutamine represses its own synthesis as shown by changes in the concentration of glutamine synthetase (GS) specific mRNA (Lara et al., 1982). However, as a measurable activity of GS is found in cells grown on glutamine (Vichido et al., 1978), it would seem that glutamine synthesis is not completely repressed and that glutamine would thus be continuously recycled.

Taking these observations into account, we studied glutamine assimilation in wild-type $N$. crassa and in mutants lacking various enzymes of the ammonium assimilation pathway.

\section{METHODS}

Strains. All stocks came from the collection of J. Mora or from the Fungal Genetics Stock Center (Humboldt State University Foundation, Arcata, Calif., USA. The basic stocks were the wild-type strain 74-A; the am-1 strain, lacking glutamate dehydrogenase $\left(\mathrm{GDH}^{-}\right)$(Fincham, 1950); the en-am-2 strain, lacking glutamate synthase (GOGAT ${ }^{-}$) (Hummelt \& Mora, $\left.1980 b\right)$; the $g$ l $n$ - $1 a$ strain, partially lacking glutamine synthetase activity (GS \pm ) (Dávila et al., 1983); the double mutant strain en-am-2; am-1 (GOGAT ${ }^{-} ; \mathrm{GDH}^{-}$) and the double mutant strain $a m-1 ; g \ln -1 a\left(\mathrm{GDH}^{-} ; \mathrm{GS} \pm\right)$.

Abbreviations: GDH, NADP-dependent glutamate dehydrogenase; GOGAT, NADH-dependent glutamate synthase; GS, glutamine synthetase. 
Growth conditions. Batch cultures of $N$. crassa were grown at $30^{\circ} \mathrm{C}$ with shaking ( 250 r.p.m.) on Vogel's minimal medium (Vogel, 1964) supplemented with $1.5 \%$ sucrose. The conidia used as inoculum were obtained as previously reported (Vichido et al., 1978). Except where stated the nitrogen source was glutamine at the concentration indicated in the text. Glutamine limitation in fed-batch cultures was achieved by pumping glutamine at a dilution rate of $0.015 \mu \mathrm{mol} \mathrm{ml}^{-1} \mathrm{~h}^{-1}$ into aerated Florence flasks held at $30^{\circ} \mathrm{C}$ containing Vogel's medium lacking nitrogen. Growth was determined as described by Vichido et al. (1978).

Ammonium and amino acid analysis, The intracellular amino acid pools and the ammonium concentration in the medium were determined as described by Espín et al. (1979).

Amino acid labelling with $\left[U^{-1+} \mathrm{C}\right]$ sucrose. Conidia from the wild-type strain or the $g \ln$ - $l a$ strain were germinated for $7.5 \mathrm{~h}$ in a medium supplemented with $5 \mathrm{~mm}$-glutamine and $1.5 \%$ sucrose. The mycelium was collected by filtration and transferred to a medium containing $5 \mathrm{mM}$-glutamine, $0.06 \%$ sucrose and $0.17 \mathrm{mCi}(6.29 \mathrm{MBq})$ $\left[\mathrm{U}-{ }^{1+} \mathrm{C}\right]$ sucrose $\mathrm{ml}^{-1}$. After $90 \mathrm{~min}$ incubation the mycelium was collected and the amino acid content was determined as reported by Espín et al. (1979); the radioactivity incorporated in each amino acid was determined in a liquid scintillation counter.

Determination of enzyme activities. GOGAT and GS activities were assayed as described previously (Hummelt \& Mora 1980a; Lara et al., 1982).

Reproducibility of results. The experiments reported were each repeated at least once; representative results are shown.

\section{RESULTS}

To investigate the involvement of GOGAT in glutamine assimilation we compared the ammonium released from glutamine and the amino acid content in a GOGAT ${ }^{-} ; \mathrm{GDH}^{-}$strain with that in a $\mathrm{GDH}^{-}$strain. The lack of GOGAT and GDH activities would lower glutamine synthesis by decreasing the intracellular glutamate pool, resulting in a higher ammonium excretion in the $\mathrm{GOGAT}^{-} ; \mathrm{GDH}^{-}$strain than in the $\mathrm{GDH}^{-}$strain; this was, in fact, found (Fig. 1).

The participation of GOGAT in glutamine assimilation was also supported by the accumulation of glutamine and by the low content of glutamate and alanine in a GOGAT ${ }^{-}$ strain (Fig. 1). GDH also contributes to the assimilation of the ammonium released from glutamine as reflected by an increase in the glutamine content and a decrease in the alanine content (Fig. 1). These effects are clearly seen in the GOGAT ${ }^{-} ; \mathrm{GDH}^{-}$strain where the glutamine pool is 100-fold higher than in the wild-type strain and where glutamate and alanine are found in very low amounts (Fig. 1). The GOGAT ${ }^{-} ; \mathrm{GDH}^{-}$strain has half the growth rate of the wild-type strain on glutamine and only grows optimally in the presence of alanine and other amino acids that can be used to synthesize glutamate by transamination (Table 1).

\section{Glutamine synthesis}

The physiological role of GS in the assimilation of ammonium coming from glutamine degradation was examined in a way similar to that described above. In comparison with the $\mathrm{GDH}^{-}$strain, the $\mathrm{GDH}^{-} ; \mathrm{GS} \pm$ strain excretes higher amounts of ammonium on glutamine as nitrogen source (Fig. 1). Also, in comparison with the wild-type, a mutant strain partially lacking GS (GS \pm ) has a similar low glutamine content, but larger glutamate and alanine pools (Fig. 1). On the other hand, the presence of the $\mathrm{GDH}^{-}$mutation in a GS \pm background causes a decrease in glutamate and alanine content (Fig. 1). These results indicate that GS also participates in the assimilation of ammonium liberated from glutamine. The low glutamine content found in the $\mathrm{GDH}^{-} ; \mathrm{GS} \pm$ strain (Fig. 1) can then be explained as the result of the operation of the $\omega$-amidase pathway, which releases ammonium that cannot be assimilated either into glutamate or into glutamine.

To determine the amount of ammonium coming from glutamine degradation by the $\omega$-amidase pathway that is assimilated by GDH and GS, we measured the amount of glutamine incorporated into the cell and the concentration of ammonium excreted by the GOGAT ${ }^{-} ; \mathrm{GDH}^{-}$strain. This strain was chosen because it does not assimilate glutamine through GOGAT and is impaired in glutamine synthesis (see above). During the first $3 \mathrm{~h}$, onefifth of the nitrogen coming from the incorporated glutamine was excreted as ammonium and from 9 to $15 \mathrm{~h}$ half of the nitrogen was excreted (Table 2). 

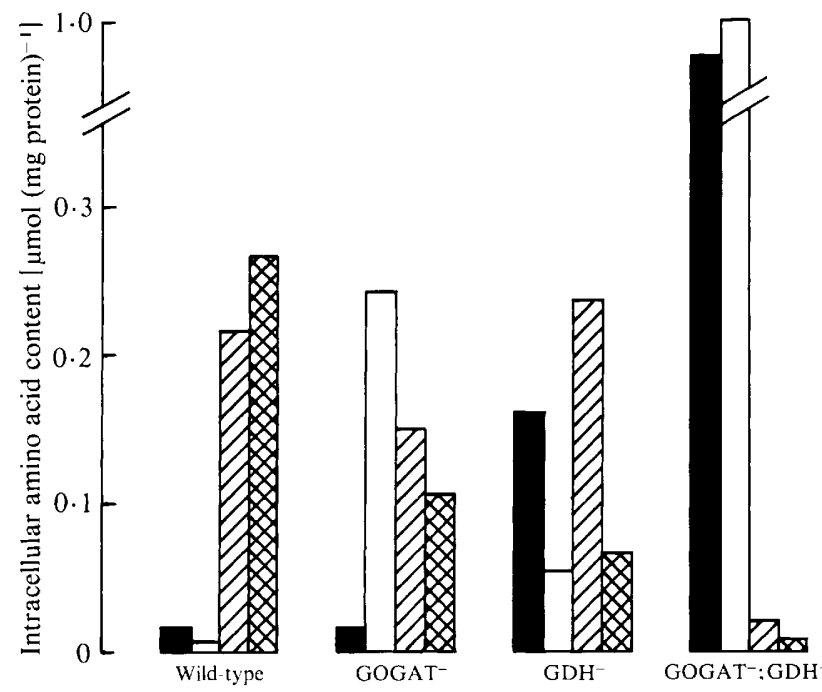

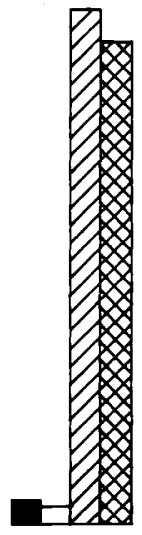

GS

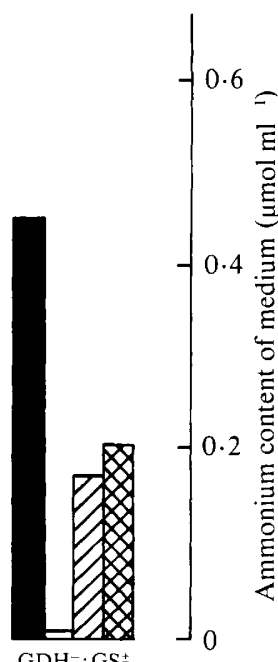

$\mathrm{GDH}^{-} ; \mathrm{GS}^{ \pm}$

Fig. 1. Amino acid intracellular pools and ammonium excretion in wild-type $N$. crassa and in mutant strains impaired in ammonium assimilation. The cultures were grown for $6 \mathrm{~h}$ on $1 \mathrm{~mm}$-glutamine. $\square$, Glutamine; $\mathbb{Z}$, glutamate; alanine; $\mathbb{a}$, extracellular ammonium.

Table 1. Growth and glutamate content in the 74- $A$ and en-am-2; am-1 strains

\begin{tabular}{|c|c|c|c|}
\hline Strain & $\begin{array}{l}\text { Nitrogen } \\
\text { source }\end{array}$ & $\begin{array}{l}\text { Doubling } \\
\text { time }(\mathrm{h})\end{array}$ & $\begin{array}{l}\text { Glutamate content* } \\
{\left[\mu \mathrm{mol}(\mathrm{mg} \text { protein })^{-1}\right]}\end{array}$ \\
\hline 74- $A$ (wild-type) & Glutamine (10 mM) & 2 & $0 \cdot 11$ \\
\hline $\begin{array}{l}\text { en-am-2;am-1 } \\
\left(\mathrm{GOGAT}^{-} ; \mathrm{GDH}^{-}\right)\end{array}$ & $\begin{array}{l}\text { Glutamine }(10 \mathrm{~mm}) \\
\text { Alanine }(10 \mathrm{~mm}) \\
\text { Aspartate }(10 \mathrm{mM}) \\
\text { Glutamine }(10 \mathrm{~mm}) \\
+ \text { alanine }(1 \mathrm{~mm})\end{array}$ & $\begin{array}{l}4 \\
2 \\
2 \\
2\end{array}$ & $\begin{array}{l}0.04 \\
0 \cdot 11 \\
0 \cdot 10 \\
0 \cdot 13\end{array}$ \\
\hline
\end{tabular}

Table 2. Glutamine uptake and ammonium excretion in the en-am-2; am-1 strain $\left(G O G A T^{-} ; G D H^{-}\right)$during growth on $1 \mathrm{mM}$-glutamine as the nitrogen source

$\begin{array}{rcc}\begin{array}{c}\text { Time } \\ (\mathrm{h})\end{array} & \begin{array}{c}\text { Glutamine } \\ \left(\mu \mathrm{mol} \mathrm{ml}^{-1}\right)\end{array} & \begin{array}{c}\text { Ammonium } \\ \left.(\mu \mathrm{mol} \mathrm{ml})^{-1}\right)\end{array} \\ 3 & 0.23 & 0.09 \\ 6 & 0.44 & 0.28 \\ 9 & 0.50 & 0.62 \\ 12 & 0.80 & 0.78 \\ 15 & 0.85 & 0.88\end{array}$

The synthesis of glutamine in the presence of glutamine as the nitrogen source was demonstrated by incubating the wild-type strain with $\left[{ }^{14} \mathrm{C}\right]$ sucrose (Table 3 ). Glutamate and glutamine were labelled as well as other amino acids like alanine and aspartate. The specific radioactivity of glutamate and glutamine was about half that of aspartate and alanine as a result of dilution by the respective non-labelled amino acid. A ninefold decrease in the radioactivity incorporated on glutamine and a fourfold decrease in its specific radioactivity were observed in the $g$ In- $I a$ strain, which partially lacks GS activity (Table 3 ). These results indicate that the 


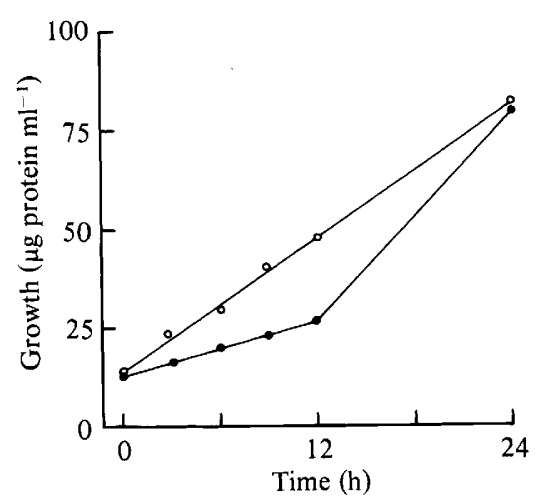

Fig. 2. Growth curves of the wild-type strain $(O)$ and the GS \pm mutant strain $(O)$ in glutamine-limited fed-batch culture.

Table 3. Distribution of label from $\left[{ }^{14} \mathrm{C}\right]$ sucrose into amino acids in the $74-A$ and gln-1a strains during growth on $5 \mathrm{mM}$-glutamine as the nitrogen source

\begin{tabular}{|c|c|c|c|c|}
\hline Strain & Amino acid & $\begin{array}{l}10^{-3} \times \text { Radioactivity } \\
\text { incorporated } \\
{\left[\text { c.p.m. }(\mathrm{mg} \text { protein })^{-1}\right]}\end{array}$ & $\begin{array}{l}\text { Amino acid content } \\
{\left[\mu \mathrm{mol}(\mathrm{mg} \text { protein })^{-1}\right]}\end{array}$ & $\begin{array}{c}10^{-3} \times \text { Specific } \\
\text { radioactivity } \\
{\left[\text { c.p.m. }(\mu \mathrm{mol} \text { amino acid })^{-1}\right]}\end{array}$ \\
\hline $74-A$ & $\begin{array}{l}\text { Aspartate } \\
\text { Glutamate } \\
\text { Glutamine } \\
\text { Alanine }\end{array}$ & $\begin{array}{l}165 \cdot 7 \\
427 \cdot 6 \\
279 \cdot 5 \\
795 \cdot 0\end{array}$ & $\begin{array}{l}0.029 \\
0 \cdot 144 \\
0 \cdot 144 \\
0 \cdot 168\end{array}$ & $\begin{array}{l}5657 \cdot 5 \\
2968 \cdot 0 \\
1941 \cdot 0 \\
4732 \cdot 0\end{array}$ \\
\hline$g \ln -1 a$ & $\begin{array}{l}\text { Aspartate } \\
\text { Glutamate } \\
\text { Glutamine } \\
\text { Alanine }\end{array}$ & $\begin{array}{r}127 \cdot 1 \\
307 \cdot 0 \\
31 \cdot 2 \\
1472 \cdot 2\end{array}$ & $\begin{array}{l}0 \cdot 019 \\
0 \cdot 188 \\
0 \cdot 073 \\
0 \cdot 132\end{array}$ & $\begin{array}{r}6760 \cdot 5 \\
1633 \cdot 0 \\
429 \cdot 8 \\
11153 \cdot 0\end{array}$ \\
\hline
\end{tabular}

labelled 2-oxoglutarate that comes from the oxidation of $\left[{ }^{14} \mathrm{C}\right]$ sucrose is sequentially converted to glutamate and glutamine. If the glutamine incorporated into the cell was sufficient to supply all of the requirements and no glutamine synthesis was necessary, we should not find any radioactivity incorporated in glutamine.

Although the $\mathrm{GS} \pm$ strain grows as well as the wild-type strain on glutamine, it grows poorly at first in limited glutamine fed-batch cultures (Fig. 2). However, after $12 \mathrm{~h}$, this mutant strain grows well in limiting glutamine (Fig. 2) and shows a fourfold increase in GS specific activity (result not shown).

\section{DISCUSSION}

GOGAT plays an important role in the assimilation of glutamine nitrogen as indicated by: (a) the accumulation of glutamine and the lower content of glutamate and alanine in a GOGAT ${ }^{-}$ strain; $(b)$ a higher accumulation of glutamine, a lower content of glutamate and alanine and a greater excretion of ammonium in the GOGAT ${ }^{-}$; $\mathrm{GDH}^{-}$strain compared to the $\mathrm{GDH}^{-}$strain; and $(c)$ the low growth rate of the GOGAT ${ }^{-} ; \mathrm{GDH}^{-}$strain on glutamine as nitrogen source and its optimal growth rate on alanine and other amino acids which yield glutamate efficiently.

The large amount of glutamine found in the GOGAT ${ }^{-} ; \mathrm{GDH}^{-}$strain can be explained by the glutamate limitation that could impair glutamine distribution as both nitrogen donors are required in some biosynthetic pathways. The slow growth on glutamine of the $\mathrm{GOGAT}^{-} ; \mathrm{GDH}^{-}$strain is the result of its inability to synthesize glutamate by GOGAT and GDH. 
The ammonium released from glutamine by the $\omega$-amidase is assimilated by GDH (Calderón et al., 1985) and GS, as indicated by: (a) the higher excretion of ammonium in the $\mathrm{GDH}^{-} ; \mathrm{GS} \pm$ strain compared to that in the $\mathrm{GDH}^{-}$strain; (b) the accumulation of glutamate and alanine in the GS \pm strain; $(c)$ the labelling of glutamine in the presence of $\left[{ }^{14} \mathrm{C}\right]$ sucrose in the wild-type strain; and $(d)$ the decrease in the labelling of glutamine in the GS \pm strain.

The excretion as ammonium of half of the nitrogen from the glutamine incorporated in the GOGAT $^{-} ; \mathrm{GDH}^{-}$strain indicates that a high proportion of glutamine is degraded to inorganic nitrogen which is assimilated back to organic nitrogen by GDH and GS. This explains why the GOGAT $^{-}$strain does not excrete ammonium on glutamine as nitrogen source.

We have shown that for glutamine to be assimilated as a nitrogen source it must be converted to glutamate, the other nitrogen donor. As shown here, the contribution of amidotransferases different from GOGAT in the assimilation of glutamine into glutamate when the former is the nitrogen source must be a minor one: thus the action of GOGAT and the incorporation of the ammonium liberated by the $\omega$-amidase pathway through GDH becomes essential.

Glutamine synthesis is required in the presence of glutamine as a nitrogen source, as indicated by the correlation between growth and GS activity in the GS \pm strain on limited glutamine as a nitrogen source. We have previously shown that the GS \pm strain has a normal GS $\alpha$ polypeptide and an altered GS $\beta$ polypeptide which inactivates GS by forming an abnormal nonfunctional hybrid oligomer (Dávila et al., 1983). This explains the low GS activity found at $12 \mathrm{~h}$ in this strain when grown on glutamine. $N$. crassa expresses preferentially the GS $\alpha$ polypeptide under conditions of nitrogen limitation (Lara et al., 1982); the increased GS activity found after $12 \mathrm{~h}$ growth could be caused by the lack of enough altered GS $\beta$ polypeptide to inactivate all the synthesized GS $\alpha$ polypeptide.

With the exception of the $\mathrm{GOGAT}^{-} ; \mathrm{GDH}^{-}$strain all the ammonium assimilation mutants grow at the same rate as the wild-type strain; however, the effects of the mutations are reflected in the amino acid pool sizes, and in the excretion of ammonium during growth on glutamine as nitrogen source. The nitrogen accumulated in amino acids is a small proportion of the total nitrogen flux. The presence of more than one pathway, the accumulation of substrate and changes in enzyme activity are some of the factors that may compensate for the enzyme deficiencies and give optimal growth. In the case of $\mathrm{GOGAT}^{-}$and $\mathrm{GDH}^{-}$strains the enzyme activity remaining must enable glutamate synthesis to occur. In the GS \pm strain, the impairment in glutamine synthesis is compensated for by the exogenous glutamine, and only in glutamine limited cultures is it reflected in a poor growth rate. Further work will be required to analyse glutamine cycling in a more quantitative manner.

Glutamine cycling also operates in the presence of ammonium as a nitrogen source, as indicated by the presence of 2-oxoglutaramate under these conditions (Calderón et al., 1985). Furthermore, we have found that a mutant strain which lacks asparagine synthetase activity grows on 2-oxosuccinamate, the 2-oxoacid of asparagine, as a result of amination by glutamine transaminase (data not shown). Studies on ammonium assimilation in Bacillus megaterium and Escherichia coli under starvation using ${ }^{13} \mathrm{~N}$ as a tracer have shown a high ammonium nitrogen turnover (Choong-Hyun \& Hollocher, 1982).

The cycling of glutamine in $N$. crassa may have several functions besides contributing to the irreversibility of glutamine transamination (Cooper \& Meister, 1977). Because glutamine is a nitrogen donor and also a corepressor of nitrogen metabolism (Marzluf, 1981), its turnover in a 'futile cycle' may be a way to rapidly regulate its intracellular concentration (Katz \& Rognstad, 1976), and thus quickly control the rate of synthesis and degradation of cellular nitrogen. In addition, the turnover of glutamine may be a general way to take up or liberate the carbon skeleton of organic nitrogenous metabolites. Finally, the turnover of glutamine to glutamate and other amino acids is a way of maintaining the optimal balance among the nitrogenous compounds (Cooper \& Meister, 1977).

We are grateful to Lorenzo Segovia for his critical review of the manuscript, to Gisela DuPont for the amino acids determination and to Maria Elena Velázquez for her technical assistance. The work was supported in part by a grant from Consejo Nacional de Ciencia y Tecnologia (CONACyT). 


\section{REFERENCES}

Calderón, J., Moretr, E. \& Mora, J. (1985). $\omega$ Amidase pathway in the degradation of glutamine in Neurospora crassa. Journal of Bacteriology 161, 807809.

Choong-Hyun, K. \& Hollocher, T. H. (1982). ${ }^{13} \mathrm{~N}$ isotope studies on the pathway of ammonia assimilation in Bacillus megaterium and Escherichia coli. Journal of Bacteriology 151, 358-366.

COOPER, A. J. L. \& Meister, A. (1977). The glutamine transaminase- $\omega$-amidase pathway. CRC Critical Reviews in Biochemistry 4, 281-303.

Dávila, G., Brom, S., Mora, Y., Palacios, R. \& Mora, J. (1983). Genetic and biochemical characterization of glutamine synthetase from Neurospora crassa glutamine auxotrophs and their revertants. Journal of Bacteriolog! 156, 993-1000.

Espí, G. \& MORA, J. (1978). Effect of the deprivation of amino acids on conidia of Neurospora crassa. Journal of General Microbiology 104, 233-240.

Espín, G., Palacios, R. \& Mora, J. (1979). Glutamine metabolism in nitrogen-starved conidia of Neurospora crassa. Journal of General Microbiology 115, 5968.

Fincham, J. R. S. (1950), Mutant strains of Neurospora deficient in aminating ability. Journal of Biological Chemistry 182, 61-73.

Hummelt, G. \& Mora, J. (1980a). NADH-dependent glutamate synthase and nitrogen metabolism in Neurospora crassa. Biochemical and Biophysical Research Communications 92, 127-133.
Hummelt, G. \& Mora, J. (1980 b). Regulation and function of glutamate synthase in Neurospora crassa. Biochemical and Biophysical Research Communications 96, 1688-1694.

KATZ, J. \& RognstaD, R. (1976). Futile cycles in the metabolism of glucose. Current Topics in Cell Regulation 10, 237-289.

lara, M., Blanco, L., Campomanes, M., Calva, E. \& MORA, J. (1982) Physiology of ammonium assimilation in Neurospora crassa. Journal of Bacteriology $\mathbf{1 5 0}$, $105-112$.

Marzluf, G. A. (1981). Regulation of nitrogen metabolism and gene expression in fungi. Microbiological Reviews 45, 437-461.

Prusiner, S. \& Stadtman, E. R. (eds) (1973). The enzymes of glutamine metabolism, pp. 331-573. New York: Academic Press.

VACA, G. \& MORA, J. (1977). Nitrogen regulation of arginase in Neurospora crassa. Journal of Bacteriology 131, 755-567.

Vichido, I., Mora, Y., Quinto, C., Palacios, R. \& MORA, J. (1978). Nitrogen regulation of glutamine synthetase in Neurospora crassa. Journal of General Microbiology 106, 251-259.

VOGEL, H. J. (1964). Distribution of lysine pathways among fungi: evolutionary implications. American Naturalist 98, 435-446. 